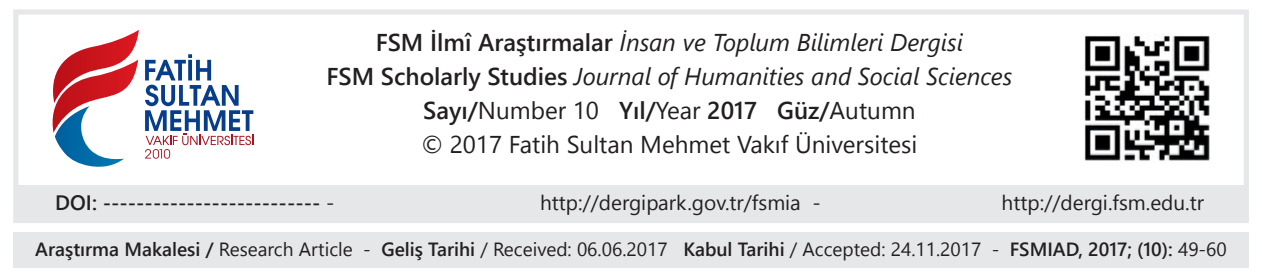

\title{
Üstbilişsel Öğretim Stratejilerinin Öğrencilerin Öz Düzenleme Becerilerine Etkisi*
}

\author{
Serhat Arslan** \\ Yücel Gelişli*** \\ $\ddot{O} z$
}

Araştırmada üstbilişsel öğretim stratejileri içeren etkinliklerin çalışmaya katılan öğrencilerde öz düzenleme becerileri ve bunların kalıcılığına etkisi araştırılmıştır. Çalışma, ön test-son test kontrol, gruplu modele göre düzenlenmiştir. Araştırmada deney ve kontrol grubunda 15 öğrenci yer almıştır. Araştırma verilerinin analizinde parametrik olmayan test teknikleri kullanılmıştır. Üstbilişsel öğretim stratejilerinin kullanıldığı deney grubundaki öğrencilerin, yapılan uygulamalar sonucunda algılanan öz düzenleme düzeylerinin arttığı sonucuna ulaşılmışı̧ı. Araştırmanın denenceleri üç ayrı zamanda toplanan veriler ile yapılan analiz sonucunda ortaya çıkan bulgular kapsamında tartı̧̧ılmıştır.

Anahtar Kelimeler: Öz düzenleme, üstbiliş, başarı.

\section{The Effects of Metacognitive Teaching Strategies on Students' Self-Regulation Skills}

\section{Abstract}

In the current study, the effects of teaching based on metacognitive teaching strategies on students' self-regulation skills were investigated. The present study was conducted according to pre-test-post-test-control group design that is one of the experimental research methods. There were 15 students in each group in the study. In data analysis, non parametric tests were used. The findings show that teaching based on metacognitive teaching strategies increased students' perceived self-regulation skills in the experimental group. Findings obtained from the statistical analyzes applied to the measurements made in three time periods were discussed in the context of the essays which constitute the basis of the research.

Keywords: Self regulation, metacognition, achievement.

* Bu çalışma ikinci yazarın danışmanlığında birinci yazarın doktora tezinden üretilmiştir.

** Yrd. Doç. Dr., Sakarya Üniversitesi Eğitim Fakültesi, Sakarya/Türkiye, serhatarslan@sakarya. edu.tr, orcid.org/ 0000-0003-4422-8421

*** Prof. Dr., Gazi Üniversitesi Eğitim Fakültesi, Ankara/ Türkiye, gelisli@gazi.edu.tr, orcid. org/0000-0003-2816-3621 


\section{Giriş}

Üstbilişe ilişkin en önemli teori, Flavell'in ilk kavramsallaştırması olarak kabul edilmektedir. Flavell, Piaget'in bellek ve zeka arasındaki bağlantısından, Brown'un çalışmasından ve Markman'ın kavrayış izlemesi gibi çalışmalardan yola çıkarak, üst biliş bilgisi, üstbiliş deneyimi, amaçlar (veya görevler) ve eylemleri (veya stratejiler) kapsayan bir üstbilişsel modeli geliştirmiştir. Flavell'a göre, üstbilişin düzenlenmesi dahil olmak üzere üstbilişsel izleme süreci, zihinsel süreçlerin sürekli değişimi ve bilişsel yolların plandan saptığında yeni stratejilerin uygun kullanımını kapsamaktadır. Flavell, bilişsel izlemenin gerçekleştiğine ilişkin dört sınıf olduğunu yaptığı çalışmasında ortaya koymaktadır. Bunlar: (a) üstbilişsel bilgi, (b) üstbilişsel deneyim, (c) üstbilişsel amaçlar veya görevler ve (d) üstbilişsel eylemler veya stratejiler olarak tanımlanmaktadır ${ }^{1}$. Flavell ${ }^{2}$ üstbilişsel bilgiyi "bilişsel varlıklar olarak insanlarla ve kapsamlı bilişsel görevleriyle, amaçlarıyla, eylemleriyle ve deneyimleriyle ilgili olan saklı dünya bilgisinin (çocuğun veya yetişkinin) ilgili bölümü” olarak tanımlamıştır. Ayrıca üstbilişsel bilginin üç temel faktörden oluştuğunu ifade etmiştir. Bunlar: (a) kişi, (b) görev ve (c) strateji' dir. Üstbilişsel bilgi, kendi bilişsel durumları, başkalarının bilişsel durumları veya genel olarak bilişin doğası hakkında saklanan bilgi olarak tanımlanmaktadır. Üstbilişsel bilgi ayrıca, farklı faktörlerin düşünmemizi etkilemek için nasıl etkileşimde bulunduğuna ilişkin bir anlayışa da kabul edilmektedir. Flavell yapmış olduğu çalışmada, bu farklı faktörleri kişi, görev ve strateji grupları olmak üzere üçe ayırmaktadır. Bireyin düşünme sürecinde başlangıcından itibaren bireye ve diğerlerine ilişkin bilgiler bulunmakta ve bu süreç insanların farklı düşündüğünü, farklı insanların düşünme hakkında farklı inançlara sahip olduğunu, farklı insanların bazı görevlerde diğerlerinden iyi olabileceğini ve dikkat, konsantrasyon ve hatırlama gibi bilişsel süreçlerin performansı nasıl etkilediğine dair bir anlayışı kapsamaktadır. Üstbilişsel bilginin kişi kategorisi, görev kategorisi ile etkileşim içinde olmakta ve üstbilişsel bilgi, kişi kategorisi, görev kategorisi ile ilişkili süreçler olarak tanımlanmaktadır. Bilişsel bir görevi yerine getirmek amacıyla bilinçli bir şekilde bellekten çağırabildiğimiz bilgiler üstbilişsel bilgiler olarak tanımlanmaktadır.

Öz düzenleme, bireyin belirli bir görevle ilgilenip ilgilenmeyeceğini belirleyen süreç olarak tanımlanmaktadır. Öz düzenlemenin görev seçme eylemi, «dönülmeyecek bir karar vermek» olarak adlandırılmaktadır. Öz düzenleme sistemi-

1 J. Flavell, "First discussant's comments: What is memory development the development of?", Human Development, 14, 1971, 272-278.

2 J. Flavell, Metacognition and cognitive monitoring. American Psychologist, 34(10), 906-911, 1979. 
nin, bilgi alanları, duyuşsal sistem içerisindeki duygusal simgeden de sorumlu olabileceğini belirlemek oldukça önemlidir. Düşünceye ilişkin diğer unsurlar, öz düzenleme içerisindeki inançlarla bağlantılı olmaları durumunda duygusal simgelere sahip olmaktadır ${ }^{3}$. Öz düzenlemeli öğrenme sürecinde birey, gözlem yapabilme, uygulama, analiz ve sentez gelişim düzeyinden geçmektedir ${ }^{4,5}$. Düşünsel işlevde üstbilişin rolü ${ }^{6}$, yapılan bir çok araştırmada çok kapsamlı bir şekilde ele alınmışıır ${ }^{7}$. Schneider ve Pressley ${ }^{8}$ yaptıkları çalışmada, zihnin işlevi hakkındaki bilgi (üstbilişsel bilgi) ve üstbiliş yordamları arasında ayrım yapmaktadır. Ayrıca, üstbilişsel bilgi, bilişsel yeterliğin bir yan ürünü ${ }^{910}$ veya üstbilişsel yordamlar aracılı̆̆ıyla bilişsel performans üzerinde önemli bir etkiye sahip bir faktör olarak kabul edilmektedir. Cornoldi ${ }^{11}$, bireyin üstbilişsel bilgisini, genel olarak zihin işlevi ve özellikle de kendi zihnine ilişkin tutumları, bilgiyi, duyguları içeren karmaşık bir sistem olarak tanımlamaktadır. Ayrıca üstbiliş bilgisi belirli stratejilerin ve kontrol süreçlerinin seçilmesini; kullanılmasını etkilemekte ve bu işlevin performans üzerinde oldukça önemli bir etkisi olmaktadır. Ayrıca Özsoy, üstbilişsel stratejileri içeren öğretimin, öğrencilerin problem çözme beceri düzeylerinde artış olduğu sonucuna ulaşmıştır ${ }^{12}$. Üstbilişsel stratejilerinin öğretilmesinin gerekliliği bu konuda yapılan çalışmaların tümünün ortak sonucu olmaktadır. Fakat yapılan çalışmaların çoğu öğrencilerin üstbilişsel stratejilerini kullanma durumları ile diğer değişkenler arasındaki ilişkiyi belirleyen betimsel araştırmalardır. Bu çalışma

3 A. Zohar, Y. J. Dori, Metacognition in Science Education: Trends in Current Research, Springer, 2012.

4 D. H. Schunk, B. J. Zimmerman, Self-regulation of learning and performance: issues and educational applications, Hillsdale, Lawrence Erlbaum associates, Inc,1994.

5 B. J. Zimmerman, "Self-efficacy: An essential motive to learn", Contemporary Educational Psychology, 25, 2000, 82-91.

6 C. Hertzog, A. E. Robinson, "Metacognition and Intelligence" ed. O. Wilhelm, R. W. Engle, Handbook of understanding and measuring intelligence, Thousand Oaks, CA, Sage, 2004, pp. 101-123.

7 W. Schneider, "The development of procedural metamemory in childhood and adolescence", ed. G. Mazzoni, T. O. Nelson, Metacognition andcognitive neuropsychology, Mahwah, NJ, Erlbaum, 1998, pp. 1-21.

8 W. Schneider, M. Pressley, Memory development between 2 and 20, New York, Springer-Verlag, 1989.

9 I. Begg, S. Duft, P. Lalonde, R. Melnick, J. Sanvito, "Memory predictions are based on ease of processing", Journal of Memory and Language, 28, 1989, 610-632.

10 S. H. Waters, W. Schneider, G. J. Borkowski, Metacognition, Strategy Use, and Instruction, London, The Guilford Press, 2009.

11 C. Cornoldi, "The impact of metacognitive reflection on cognitive control" ed. G. Mazzoni, T. O. Nelson, Metacognition and cognitive neuropsychology, Mahwah, NJ, Erlbaum, 1998, pp. 139-159.

12 Gökhan Özsoy, "İlköğretim beşinci sınıfta üstbiliş stratejilerinin öğretiminin problem çözme başarısına etkisi”, (Yayımlanmamış Doktora Tezi), Gazi Üniversitesi, Ankara, 2007. 
üstbilişsel öğretim stratejilerinin eğitimde uygulama sürecinde etkililiğini ortaya koyması açısından önemlidir.

\section{Yöntem}

Çalışma ön test-son test kontrol, gruplu deneme modeline göre düzenlenmiştir. Deneysel çalışmalarda, bağımlı değişkenleri etkileyen ancak araştırmada etkisi araştırılmayan karıştırıcı faktörlerin olası etkilerini kontrol altına almak, dikkat edilmesi gereken önemli bir noktadır. Çalışmanın örneklemini 30 ilköğgretim 7.sınıf öğrencisinden oluşmaktadır. Yedinci sınıfın seçilmesinin diğer bir nedeni ise, sekizinci sınıfta orta öğretime hazırlanma telaşının deney çalışmalarını etkilemesini en az düzeye indirgeme gerekliliğidir ${ }^{13}$. Uygulama, üstbilişsel öğretim stratejileri içeren etkinliklerin uygulanacağ deney ve kontrol grubu ile 6 hafta boyunca gerçekleşmiştir. Öğrencilerin gruplara göre dağ 11 lımı incelendiğinde deney ve kontrol grubunda 15 öğrenci yer almaktadır.

Deney ve kontrol gruplarında yer alan bireylerin deneysel işlemin uygulanması öncesinde Algılanan Üstbilişsel Öğrenme Envanteri ön-test ölçümlerinden elde ettikleri puanların ortalamaları arasında anlamlı bir farklılık olup olmadığını test etmek amacıyla, Mann-Whitney U testi uygulanmıştır. Deney ve kontrol gruplarının algılanan Öz-Düzenleme Ölçeği ön-test puanlarına ilişkin Mann-Whitney $\mathrm{U}$ testi analiz sonuçlarından elde edilen bulgular Tablo 1'de gösterilmiştir.

Tablo 1. Mann-Whitney U testi Analiz Sonuçları

\begin{tabular}{lcccccc}
\hline Grup & $\mathrm{n}$ & Sira toplamı & Sira ortalamas & $U$ & $z$ & $p$ \\
\hline Deney & 15 & 242,0 & 16,13 & & & \\
Kontrol & 15 & 223,0 & 14,87 & 103 &, 397 &, 692 \\
Toplam & 30 & & & & & \\
\hline
\end{tabular}

Tablo 1 incelendiğinde, Mann-Whitney U testi sonuçlarına göre deney grubu ve kontrol grubunda yer alan bireylerin algılanan öz-düzenleme ölçeği ön-test ölçümlerinden aldıkları puanların ortalamaları arasında anlamlı bir farkın olmadığı görülmektedir $(\mathrm{u}=103,0 ; \mathrm{p}>0.05)$.

13 Özden Demir, "Bilişsel koçluk yöntemiyle öğretilen bilişsel farkındalık stratejilerinin altıncı sınıf sosyal bilgiler dersinde öğrencilerin epistemolojik inançlarına, bilişsel farkındalık becerilerine, akademik başarılarına ve bunların kalıcılıklarına etkisi”, (Yayımlanmamış Doktora Tezi), Çukurova Üniversitesi, Adana, 2009. 


\section{Veri Toplama Araçları}

Araştırmada katılımcıların demografik özelliklerini (yaş, cinsiyet,sınıf) belirleyebilmek amacıyla araştırmacı tarafından hazırlanan Demografik Bilgi Formu; öz düzenleme düzeylerini belirleyebilmek amaciyla Algılanan Öz düzenleme Ölçeği kullanılmıştır.

$\mathrm{Bu}$ form, araştırma kapsamında yer alan öğrencilerin temel demografik özelliklerini saptayabilmek amacıyla araştırmacının kendisi tarafından hazırlanmıştır. 3 sorudan oluşan formla araştırmaya katılan öğrencilerin cinsiyeti, yaşı, sınıfı belirlenmeye çalışılmıştır. Araştırmacı tarafından geliştirilen öz düzenleme ölçeği güvenirlik analiz sonuçları ölçeğin toplamı için .90, "Açık olma" alt boyutu için .80, "Arayış" alt boyutu için .85 bulunmuştur. Ölçekteki maddelerin faktör yükleri $.55-.75$ arasında değişmektedir $\left(\mathrm{x}^{2}=147.60, \mathrm{Sd}=95, \mathrm{NFI}=.98, \mathrm{SRMR}=.035, \mathrm{R}-\right.$ $\mathrm{MSEA}=.042, \mathrm{CFI}=.99, \mathrm{IFI}=.99, \mathrm{GFI}=.94, \mathrm{AGFI}=.92)$.

\section{Verilerin Toplanması}

Bu bölümde, pilot uygulama, deney ve kontrol gruplarında yürütülen öğretim süreçleri ile ilgili bilgiler verilmektedir. Birinci aşamada çalışmanın işlem basamakları açıklanmıştır. Deney grubunda yürütülen öğretim süreci ve kontrol grubunda yürütülen öğretim süreci anlatılmıştır. Tasarlanan öğrenme ortamının uygulaması, Milli Eğitim Bakanlığına bağlı bir okulda öğrenim gören 15 öğrenci ile yürütülmüştür. Hava kirliliği ve radon gazı, doğal yaşamı koruma, insan ve biyolojik çeşitlilik, iklim değişikliği ve asit yağmuru ve doğal yaşlı ormanlar etkinlikleri insan ve çevre ünitesi kapsamında ele alınmıştır. Asit yağmuru / İklim Değişikliği ünitesi ile ilgili olarak; bitkilerin büyümesinde iklimsel faktörlerin bitkilerin büyümesi ve gelişmesi üzerindeki etkilerini incelemek amacıyla; öğretmen öğrencileri deney düzeneklerini oluşturmalarından önce 5 gruba böler ve üstbiliş stratejilerden işbirliği ve amaç düzenleme ve sürdürme tekniğini kullanır. Hava kirliliği ünitesi ile ilgili olarak kapalı mekânlarda hava kirliliğine sebep olan gazlar ile ilgili olarak "Görünmez Gaz saldırısı" başlıklı okuma metni Üstbiliş stratejilerden "karşılıklı öğretim stratejisi” kullanılarak" okuma metni okunur. Biyolojik çeşitlilik ünitesi ile ilgili olarak düşünme soruları kapsamında öğrenciler ile beyin firtınası yapılır. Doğal yaşlı ormanlar ünitesi ile ilgili olarak rol yapma stratejisi kapsamında; sınıf içerisinden bir öğrenci belediye başkanı rolünde; sınıf içerisinden seçilecek 5 öğrenci ise İl meclis üyesi rolünü oynayarak "En bilge ormanlar: Doğal yaşlı ormanlar" okuma metni çerçevesinde öğrenci fikirleri paylaşılır. Doğal yaşamı koruma ünitesi ile ilgili olarak; öğrenciler doğal yaşamı korumaya yönelik kural önerilerini belirtip bu önerilerini doğal yaşam, su kaynakları, bitki ve hayvan yaşamı, ekonomik, sosyal, toplumsal, açıdan etkileri neler olabileceği üzerinde fikirlerini belirtir. 


\section{Bulgular \\ Ön Analiz Sonuçları}

Araştırmanın nicel verilerinin çözümlenmesinde, varyansların homojenliği ve verilerin normal dağılıma uygunluğu incelenmiştir. Bu şartların sağlanıp sağlanmadığını belirlemek amaciyla, öncelikle hem deney hem de kontrol grubunda bulunan bireylerin, algılanan Öz-Düzenleme Ölçeği formundan aldıkları puanlar açısından birbirlerine denk olup olmadıklarını saptamak için varyansların homojenliği incelenmiştir. Homojenlik testinden elde edilen sonuçlar, grupların varyanslarının algılanan Özdüzenleme Ölçeği formundan aldıkları puanlar açısından birbirine denk olduğunu göstermiştir. Homojenlik testine ilişkin bulgular Tablo 3'de verilmiştir.

Tablo 2. Homojenlik Testi Analiz Sonuçları

\begin{tabular}{lcccc}
\hline Değişken & $\begin{array}{c}\text { Levene } \\
\text { Statistic }\end{array}$ & sd1 & sd2 & $p$ \\
\hline $\begin{array}{l}\text { Ön-test Algılanan Öz-Düzenleme } \\
\text { Ölçeği }\end{array}$ & .162 & 1 & 28 & .691 \\
\hline
\end{tabular}

$p<0.05$

Tablo 2'de görüldüğü gibi, deney ve kontrol gruplarında bulunan bireylerin; Algilanan Öz-Düzenleme Ölçeği ön-test ölçümlerine yönelik varyans analizinden elde edilen sonuçlar her iki grupta yer alan bireylerin, Öz düzenleme ölçeği $\left(\mathrm{F}_{1-28}=.162, \mathrm{p}>.05\right)$ ön-test ölçümlerinden aldıkları puanlar arasında anlamlı bir fark olmadığını göstermiştir.

\section{Öz Düzenleme Becerilerine Yönelik Denencelerin Test Edilmesi}

Araştırmaya katılan öğrencilerin öz düzenleme ölçeği ön test-sontest-izleme testi puan sıralamaları için Friedman Two way Anova testi uygulanmıştır. Analiz sonucu Tablo 3'de verilmiştir.

Tablo 3. Friedman Two way Anova testi analiz sonuçları

\begin{tabular}{lccccc}
\hline Testler & N & Sira ortalamas1 & Serbestlik dercesi & $X^{2}$ & $p$ \\
\hline Ön test & 15 & 1,00 & 2 & 23,33 &, $00^{*}$ \\
Son test & 15 & 2,67 & & & \\
İzleme testi & 15 & 2,33 & & & \\
\hline
\end{tabular}


Tablo 3 incelendiğinde, deney grubunda yer alan öğrencilerin deneysel uygulama öncesi, deneysel uygulama bitiminde ve izleme sürecinde uygulanan öz düzenleme ölçeğinden almış oldukları puanların sıralamaları arasında anlamlı bir fark bulunmuştur $\left(X^{2}=23,33, p=, 00\right)$.

Deney grubunda yer alan öğrencilerin öz düzenleme ölçeği son test ve ön test puanlarına ilişkin Wilcoxon işaretli sıralar testi uygulanmıştır. Analiz sonucu Tablo 4'de verilmiştir.

Tablo 4. Wilcoxon işaretli sıralar testi analiz sonuçları

\begin{tabular}{lcccccc}
\hline Son test-Ön test & $\mathrm{N}$ & Sira toplamı & Sira ortalamas1 & Eta kare & $Z$ & $p$ \\
\hline Negatif sira & 15 &, 00 &, 00 & 0,84 & $-3,413^{* *}$ &, $001^{*}$ \\
Pozitif sira & 15 & 120,0 & 8,0 & & & \\
Toplam & 30 & & & & & \\
\hline
\end{tabular}

${ }^{*} p<0.05 ; * *$ Negatif siralar temeline dayal

Analiz sonuçları araştırmaya katılan öğrencilerin algılanan öz düzenleme ölçeğinden aldıkları ön test ve son test puanları arasında anlamlı bir fark vardır $(\mathrm{Z}=-3.413 ; \mathrm{p}=, 001)$.

Araştırmaya katılan öğrencilerin algılanan öz düzenleme ölçeğinden aldıkları ön test ve izleme testi puanlarına ilişkin Wilcoxon işaretli sıralar testi uygulanmıştır. Analiz sonucu Tablo 5 'de verilmiştir.

Tablo 5. Wilcoxon işaretli sıralar testi analiz sonuçları

\begin{tabular}{lcccccc}
\hline İzleme testi-Ön test & $\mathrm{N}$ & Sira toplamı & Sira ortalaması & Eta kare & $Z$ & $p$ \\
\hline Negatif sıra & 15 &, 00 &, 00 & 0,81 & $3,41^{* *}$ &, $001^{*}$ \\
Pozitif sıra & 15 & 120,0 & 8,0 & & & \\
Toplam & 30 & & & & & \\
\hline
\end{tabular}

${ }^{*} p<0.05 ; * *$ Negatif siralar temeline dayalı

Analiz sonuçları araştırmaya katılan öğrencilerin algılanan öz düzenleme ölçeğinden aldıkları ön test ve izleme testi puanları arasında anlamlı bir fark oldugunu göstermektedir ( $Z=3.41 ; \mathrm{p}=, 001)$.

Araştırmaya katılan öğrencilerin algılanan öz düzenleme ölçeğinden aldıkları son test ve izleme testi puanlarına ilişkin Wilcoxon işaretli sıralar testi uygulanmıştır. Analiz sonucu Tablo 6'da verilmiştir. 
Tablo 6. Wilcoxon işaretli sıralar testi analiz sonuçları

\begin{tabular}{lcccccc}
\hline Son test-İzleme testi & $\mathrm{n}$ & Sira toplamı & Sira ortalamas1 & Eta kare & $z$ & $p$ \\
\hline Negatif sıra & 15 & 82,00 & 8,20 & & $1,254^{* *}$ &, 210 \\
Pozitif sıra & 15 & 38,00 & 7,60 & & & \\
Toplam & 30 & & & & & \\
\hline
\end{tabular}

$* p<0.05 ; * *$ Negatif siralar temeline dayal

Analiz sonuçları araştırmaya katılan öğrencilerin algılanan öz düzenleme ölçeğinden aldıkları izleme ve son test puanları arasında anlamlı bir farkın olmadığını göstermektedir ( $Z=1.254 ; \mathrm{p}=, 210)$.

\section{Tartışma, Sonuç ve Öneriler}

$\mathrm{Bu}$ araştırmada, üstbiliş stratejileri içeren etkinliklerin, öğrencilerin algılanan öz düzenleme becerilerine etkisi incelenmiştir. Araştırma sonucunda, deney ve kontrol gruplarındaki bireylerin ön-test, son-test ve izleme ölçümlerinde aldıkları puanlar deney grubu lehine değişmektedir.

Yapılan literatür incelemesinde Vuk ${ }^{14}$ üstbilişsel beceri, öz yeterlilik ve sınav kaygısına araştırmasında, üniversite öğrencilerinin öz düzenlemeleri üzerinde bilişsel farkındalık yeteneği ve yardımın oldukça önemli bir etkisi olduğu sonucuna ulaşmaktadır. Ayrıca, Türkiye'de üstbiliş alanında yapılan çalışmalarda, çeşitli öğretim yöntemlerinin kullanılmasıyla üstbilişsel becerilerin gelişip gelişmediği ve ünite başarısı üzerindeki etkisi araştırılmıştı1 ${ }^{15,16,17}$. Alemdar, konuya entegre edilen bilişüstü beceri eğitiminin ünite başarısını arttırmada, üstbilişsel becerilerin doğru kavram kazanımında etkili olduğuna ve kavramların sürekliliği ve transfer becerilerinin geliştiği bulunmuştur. Ayrıca, Çalışkan, uygulanan öğrenme stratejileri öğretimi öğrencilerin öğrenme stratejileri farkındalıklarını,

14 J. Vuk, "College students' behavior on multıple choice self-tailored exams in relation to metacognitive ability, self-efficacy and test anxiety", (Unpublished Ph. Thesis), Mississippi State University Depertmant of Counseling and Educational Psychology, USA, 2008.

15 Arzu Alemdar, "Bilişüstü beceri eğitiminin fen bilgisi öğrencilerinin başarılarına, kavram kazanımlarına, kavramlarının sürekliliğine ve transferine etkisi”, (Yayımlanmamış Doktora Tezi), Marmara Üniversitesi, İstanbul, 2009.

16 Muhittin Çalışkan, “Öğrenme stratejileri öğretiminin yürütücü biliş bilgisine, yürütücü biliş becerilerini kullanmaya ve başarıya etkisi”, (Yayımlanmamış Doktora Tezi), Selçuk Üniversitesi Eğitim Bilimleri Enstitüsü, Konya, 2009.

17 Mehmet Kürşad Duru, "İköğretim fen bilgisi dersinde beyin firtınası ile öğretimin başarıya, kavram öğrenmeye ve bilişüstü becerilere etkisi”, (Yayımlanmamış Doktora Tezi), Marmara Üniversitesi, İstanbul, 2007. 
yürütücü biliş bilgilerini, yürütücü biliş becerilerini ve başarıyı arttırdığı sonucuna ulaşmıştır. Demir, yapmış olduğu çalışmada bilişsel koçluğa dayalı bilişsel farkındalık stratejileri temel alınarak yapılan öğretimin öğrencilerin başarılarını ve bilişsel farkındalık düzeylerini artırdığını sonucuna ulaşmıştır. Duru, beyin firtınası ile işlenen fen bilgisi dersinin öğrencilerin akademik başarıları ve kavram öğrenmelerindeki pozitif değişime etkisi olduğu sonucuna ulaşmıştır. Üstbilişsel stratejilerin tüm bu değişkenlerle ilişkileri göz önünde bulundurulduğunda, bu bulguların araştırma sonuçlarını destekler nitelikte olduğu görülmektedir. Araştırmanın önerileri kapsamında; akademik başarısı düşük, dersle ilgisi olmayan ve öğrenmeden ziyade performans başarı yönelimlerini benimsemiş öğrencilerin davranışları öğretmen ve ebeveynlerce gözlenip ve bu öğrencilerin üstbilişsel stratejileri kullanıyor olabileceklerine ilişkin farkındalık sağlanabilir. Ayrıca, hazırlanan üstbilişsel etkinlikler öğrencilerin başarı seviyelerine göre bireyselleştirilebilir, her düzeyden öğrencinin kendine göre gelişmesi sağlanabilir. Böylelikle üstbiliş staretijileri içeren etkinliklerden fayda sağlamadığını düşünen öğrencilerin de sürece dahil olması sağlanabilir. 


\section{Kaynakça}

Alemdar, Arzu, "Bilişüstü beceri eğitiminin fen bilgisi öğrencilerinin başar1larına, kavram kazanımlarına, kavramlarının sürekliliğine ve transferine etkisi”, (Yayımlanmamış Doktora Tezi), Marmara Üniversitesi, İstanbul, 2009.

Begg, I., Duft, S., Lalonde, P., Melnick, R., Sanvito, J., "Memory predictions are based on ease of processing", Journal of Memory and Language, 28, 1989.

Cornoldi, C., "The impact of metacognitive reflection on cognitive control", ed. G. Mazzoni, T. O. Nelson, Metacognition and cognitive neuropsychology, Mahwah, NJ, Erlbaum, 1998.

Çalışkan, Muhittin, "Öğrenme stratejileri öğretiminin yürütücü biliş bilgisine, yürütücü biliş becerilerini kullanmaya ve başarıya etkisi”, (Yayımlanmamış Doktora Tezi), Selçuk Üniversitesi Eğitim Bilimleri Enstitüsü, Konya, 2009.

Demir, Özden, "Bilişsel koçluk yöntemiyle öğretilen bilişsel farkındalık stratejilerinin altıncı sınıf sosyal bilgiler dersinde öğrencilerin epistemolojik inançlarına, bilişsel farkındalık becerilerine, akademik başarılarına ve bunların kalıcılıklarına etkisi”, (Yayımlanmamış Doktora Tezi), Çukurova Üniversitesi, Adana, 2009.

Duru, Mehmet Kürşad, "İlköğretim fen bilgisi dersinde beyin firtınası ile öğretimin başarıya, kavram öğrenmeye ve bilişüstü becerilere etkisi”, (Yayımlanmamış Doktora Tezi), Marmara Üniversitesi, İstanbul, 2007.

Flavell, J., "First discussant's comments: What is memory development the development of?", Human Development, 14, 1971.

, "Metacognition and cognitive monitoring", American Psychologist, 34(10), 1979.

Hertzog, C., Robinson, A. E., "Metacognition and Intelligence", ed. O. Wilhelm, R. W. Engle, Handbook of understanding and measuring intelligence, Thousand Oaks, CA, Sage, 2004.

Oruç, Ayşe, “Öz düzenlemeli öğrenmenin okuduğunu anlamaya tutuma ve üst bilişsel düşünmeye etkisi”, (Yayımlanmamış Yüksek Lisans Tezi), Bülent Ecevit Üniversitesi Sosyal Bilimler Enstitüsü, Zonguldak, 2012.

Özsoy, Gökhan, “İlköğretim beşinci sınıfta üstbiliş stratejilerinin öğretiminin problem çözme başarısına etkisi”, (Yayımlanmamış Doktora Tezi), Gazi Üniversitesi, Ankara, 2007.

Schneider, W., "The development of procedural metamemory in childhood and adolescence", ed. G. Mazzoni, T. O. Nelson, Metacognition andcognitive 
neuropsychology, Mahwah, NJ, Erlbaum, 1998.

Schneider, W., Pressley, M., Memory development between 2 and 20, New York, Springer-Verlag, 1989.

Schunk, D. H., Zimmerman, B. J., Self-regulation of learning and performance: issues and educational applications, Hillsdale, Lawrence Erlbaum associates, Inc, 1994.

Vuk, J. “College students' behavior on multıple choice self-tailored exams in relation to metacognitive ability, self-efficacy and test anxiety", (Unpublished $\mathrm{Ph}$. Thesis), Mississippi State University Depertmant of Counseling and Educational Psychology, USA, 2008.

Waters, S .H., Schneider, W., Borkowski, G. J., Metacognition, Strategy Use, and Instruction, London, The Guilford Press, 2009.

Zimmerman, B. J., "Self-efficacy: An essential motive to learn", Contemporary Educational Psychology, 25, 2000.

Zohar, A., Dori, Y. J., Metacognition in science education: Trends in current research, Springer, 2012. 


\section{Algılanan Öz-Düzenleme Ölçeği}

\begin{tabular}{|c|c|c|c|c|c|c|}
\hline & $\begin{array}{l}\text { Lütfen aşağıdaki ifadeleri okuduktan sonra kendinizi } \\
\text { değerlendirip sizin için en uygun seçeneğin karşısına çarpı } \\
\text { (X) işareti koyunuz. .Her ifadenin karşısında bulunan; "1" } \\
\text { Hiç bir zaman, "2" Nadiren, "3" Arasıra, "4" Siksık, "5" Her } \\
\text { zaman" anlamına gelmektedir. }\end{array}$ & 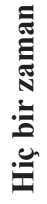 & 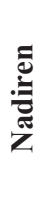 & $\begin{array}{l}\underset{5}{5} \\
\underset{5}{*}\end{array}$ & $\frac{y}{\bar{n}}$ & 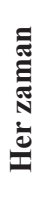 \\
\hline 1 & Eğer istersem en zor konuları bile rahatlıkla öğrenebilirim & 1 & 2 & 3 & 4 & 5 \\
\hline 2 & $\begin{array}{l}\text { Belirlediğim hedefler doğrultusunda çalışmalarımı } \\
\text { yapabilirim }\end{array}$ & 1 & 2 & 3 & 4 & 5 \\
\hline 3 & Yeni bir konuyu rahatlıkla öğrenebilirim & 1 & 2 & 3 & 4 & 5 \\
\hline 4 & $\begin{array}{l}\text { Bir konuyu anlamadığım zaman arkadaşlarımdan yardım } \\
\text { isterim }\end{array}$ & 1 & 2 & 3 & 4 & 5 \\
\hline 5 & Bir konuyu öğrenirken yenilikleri kolaylıkla fark edebilirim & 1 & 2 & 3 & 4 & 5 \\
\hline 6 & $\begin{array}{l}\text { Bir şeyler istemediğim şekilde giderse bu durum beni } \\
\text { rahatsız eder }\end{array}$ & 1 & 2 & 3 & 4 & 5 \\
\hline 7 & Hatalarımdan öğrenebilirim & 1 & 2 & 3 & 4 & 5 \\
\hline 8 & $\begin{array}{l}\text { Bir konuyu öğrenirken o dersteki notlarıma bakarak başarımı } \\
\text { sorgularım }\end{array}$ & 1 & 2 & 3 & 4 & 5 \\
\hline 9 & Bir konuyu öğrenirken farklı yollar bulmaya çalışırım & 1 & 2 & 3 & 4 & 5 \\
\hline 10 & Başarısız olduğumda çalışma yöntemimi değiştiririm & 1 & 2 & 3 & 4 & 5 \\
\hline 11 & Hedeflerime doğru ilerleme sürecimi takip edebilirim & 1 & 2 & 3 & 4 & 5 \\
\hline 12 & $\begin{array}{l}\text { Bir konuyu öğrenirken karşılaştığım problemlerin çözümü } \\
\text { için farklı yollar geliştiririm }\end{array}$ & 1 & 2 & 3 & 4 & 5 \\
\hline 13 & Bir konuyu öğrenirken yapmış olduğum plana uyarım & 1 & 2 & 3 & 4 & 5 \\
\hline 14 & Bir konuyu öğrenirken başka yöntemler kullanmaya çalışırım & 1 & 2 & 3 & 4 & 5 \\
\hline 15 & $\begin{array}{l}\text { Çoğu zaman bir konuyu öğrenirken neler yaptığıma dikkat } \\
\text { ederim }\end{array}$ & 1 & 2 & 3 & 4 & 5 \\
\hline 16 & $\begin{array}{l}\text { Yanlış öğrendiğimi fark ettiğim bir şeyi değiştirmek için } \\
\text { birçok farklı yolu deneyebilirim }\end{array}$ & 1 & 2 & 3 & 4 & 5 \\
\hline
\end{tabular}

